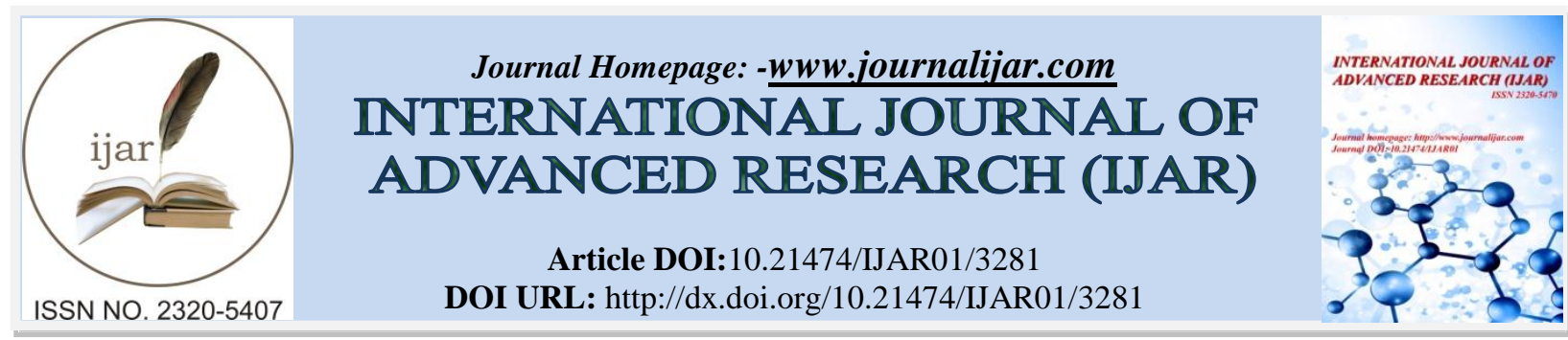

RESEARCH ARTICLE

\title{
MEASUREMENT OF OXIDANT- ANTIOXIDANT MARKERS IN PREMATURE NEWBORN WITH RESPIRATORY DISTRESS SYNDROME.
}

\author{
Ali K Al-Zahrani ${ }^{1,2}$,Nader M Mohamed ${ }^{1,3}$ and Mona G Amer ${ }^{4,5}$. \\ 1. Department of Pediatrics, college of Medicine, Taif University, Taif, Saudi Arabia. \\ 2. Department of Neonatology, King Abdel Aziz Specialist Hospital (KAASH),Taif, Saudi Arabia. \\ 3. Department of Pediatrics \& Neonatology, AlAhrar teaching Hospital, Zagazig, Egypt. \\ 4. Department of Anatomy \& Histology, College of Medicine, Taif University, Taif, Saudi Arabia. \\ 5. Department of Histology \& Cell Biology, Faculty of Medicine, Zagazig University, Egypt.
}

\section{Manuscript Info}

Manuscript History

Received: 10 December 2016

Final Accepted: 25 January 2017

Published: February 2017

Key words:-

Neonatal respiratory distress syndrome,

Oxidative stress, Antioxidant.

\section{Abstract}

Background: Respiratory distress syndrome (RDS) is still an important problem in treatment of preterm infants. The imbalance between the oxidative forces and the antioxidant defense systems was suggested to predispose the lungs to the development of RDS. The present study aimed to investigate the alterations in biochemical parameters of oxidant/antioxidant and its role in development of neonatal RDS.

Methods: This case control study included 40 premature neonates with RDS and 50 healthy premature newborns. Quantification of levels of malondialdehyde (MDA), thiobarbituric acid reacting substances (TBARS) along with total antioxidant capacity (reduced glutathione, and superoxide dismutase SOD) in cord blood of healthy premature newborns compared with those with RDS.

Results: Status of markers of oxidative stress (MDA, and TBARS) showed a significant increase with depleted levels of total antioxidant capacity of reduced glutathione and SOD in neonatal RDS when compared to healthy newborns.

Conclusion: The study concluded oxidative damage and diminished antioxidant defenses in newborns with RDS that was evidenced in severe cases of RDS. This could be of clinical significance in studying the pathophysiology of neonatal RDS.

Copy Right, IJAR, 2017,. All rights reserved.

\section{Introduction:-}

Respiratory distress syndrome ofnewborn also called Infant respiratory distress syndrome (IRDS), previously called hyaline membrane disease (HMD), is caused by lungimmaturity and insufficient production of surfactant during development. IRDSaffects about $1 \%$ of newborn infants and is the leading cause of deathin preterm infants (Rodriguez et al., 2002).

A fully developed lung is protected with defense lines that increase resistance to highO2 tensions. On contrast premature lung is affected by insufficient/dysfunctional surfactant resulting in collapsed alveoli, atelectasis, ventilation-perfusion mismatching, and subsequent hypoxemia and respiratory acidosis. The poorly developed 
peripheral airways and immaturity of cells important for lung maturation are the major causes of poor surfactant production by type II cells and inadequate antioxidant responses to increased ambient oxygen(Gleason et al., 2012). In addition to prematurity, premature neonates could be complicated by diminished antioxidant stores and antioxidant enzymes production. Oxidative stress is oxidant/antioxidant imbalances that resulting in production of free radicals. Adequately mature and healthy infants are able to tolerate this drasticchange in the oxygen concentration. A problem occurs when theintrauterine development is incomplete or abnormal. Preterm infants are typically of this kind (Rahal et al., 2014; Marseglia et al., 2014). After birth, sudden increase in oxygen supply lead to overproduction of ROS and depletion of antioxidants. Oxidant stress promote expression of cytokines and the inflammatory process (interleukin-6, interleukin- 8 , and tumor necrosis factor- $\alpha$ ) (Gitto et al., 2004; Mutinati et al., 2014).

Oxidative stress in infantsis implicated in the pathogenesis of the major complications of prematurityincluding respiratory distress syndrome (RDS), necrotizing enterocolitis, chronic lung disease, retinopathy of prematurity andintraventricular hemorrhage (Mutinati et al., 2014).

Newborns and especially pre-term infants are probably more prone to oxidative stress than are children and young adults as they are exposed to high oxygen concentrations, have infections or inflammation, have reduced antioxidant defense, and have free iron which enhances the Fenton reaction leading to production of highly toxic hydroxyl radicals (Saugstad, 2003; Saugstad, 2005). Phagocytes such as neutrophils are activated when stimulated by microorganisms or other means which increase their oxidative metabolism. If these toxic products are not inactivated, cell injury and respiratory cell death will induce (Esteban et al., 1999). Under these conditions, a surfactant deficiency may be aggravated by inactivation of the small amount of endogenous surfactant that is produced (Boda et al., 1998). Furthermore, if exogenous surfactant is given this may also be destroyed (Ikegami et al., 2000; Huertas et al., 1198).

For instance, the superoxide dismutase (SOD) activity appears in the developing lungs concomitantly with the surfactant synthesis by type II pneumocytes. So, the current study investigated the alterations in the biochemical parameters of oxidant/antioxidant by quantification of levels of malondialdehyde (MDA),TRBAS along with total antioxidant capacity in cord blood of healthy premature newborns compared with those with RDS.Umbilical cord blood provides valuable information regarding the status of the infant at birth thatgives early predictors of some of the metabolic disorders in future adult life.

\section{Patients and methods:-}

A total of 90 neonates were included in this case- control study. They were recruited from Neonatology department of King Abdul Aziz specialist Hospital (KAASH) Taif, Saudi Arabia, between August 2015 and september 2016. This study was approved by the Institutional Ethics Committee, and written informed consent for participation was obtained from the parents.

Cord blood samples were collected at the time of the delivery. The study group consisted of 40 preterm born $<33$ weeks gestational age or of low birth weight $<1500 \mathrm{~g}$ with diagnosis of RDS. The control group was composed of 50 preterm low birth weight newborns. Exclusion criteria of the study were infection, congenital malformations, metabolic disorder and newborns with history of difficult delivery, genetic disorder, severe intraventricular hemorrhages, congenital hemolytic diseases caused by blood-type incompatible pregnancies, diseases requiring surgical treatment, and a gestational age of $22 \mathrm{wk}$.

RDS was diagnosed on the presence of typical clinical and radiological signs of the disease in the preterm infants. Newborns were considered to have RDS if they have tachypnea; grunting and cyanosis with several hours of birth required mechanical ventilation and typical radiographic findings on the chest X-ray. The diagnosis was established from the clinical symptoms and needed for oxygen treatment.RDS neonates were classified into mild, moderate and severe categories based on severity of oxygenation compromise.

Maternal age, date of last menstrual period, medical history and reproductive history were obtained from the hospital record.

Four $\mathrm{mL}$ of heparinized venous blood sample was collected from the umbilical cord just after delivery of the studied neonates and processed for the isolation of erythrocytes and plasma. The red cells were stored at $4^{\circ} \mathrm{C}$ and all serum 
samples at $-20^{\circ} \mathrm{C}$ until analysis. The red cell samples were processed within 12 hours. For reduced glutathione determination erythrocyte mass was used, superoxide dismutase activity was determined in erythrocyte lysate (add 3 $\mathrm{ml} 0.9 \% \mathrm{NaCl}$ to $500 \mu \mathrm{l}$ of blood and centrifuge $660 \mathrm{~g} / 10 \mathrm{~min}$ at $4{ }^{\circ} \mathrm{C}$, remove supernatant and repeat 4 times; after final removal of supernatant add $1.5 \mathrm{ml}$ of chilled distilled water, leave for $20 \mathrm{~min}$ and freeze).

The following oxidant/antioxidant markers were measured

Serum malondialdehyde (MDA) marker of lipid peroxidationwas measured using the colorimetric method described by Satoh et al. (1978), based upon the reaction of thiobarbituric acid (TBA) with MDA, one of the aldehyde products of lipid peroxidation. The absorbance of the MDA-TBA adduct thus produced was measured at $532 \mathrm{~nm}$ wavelength using a spectrophotometer.

serum superoxide dismutase (SOD) in erythrocytes was determined by the method described by Marklund and Marklund (1974) as modified by Nandi and Chatterjee (1988), which is based on the inhibition of pyrogallol autoxidation brought about by SOD.

Reduced glutathione (GSH) was estimated by a method based on the development of yellow color with 5, 5' dithiobis-2-nitrobenzoic acid (DTB), which was measured at 432 um using a spectrophotometer (Beutler et al., 1963).

\section{Statistical analysis:-}

Descriptive analysis was performed for demographic and clinical characteristics of the patients. MDA, TBRAS, reduced glutathione and superoxide dismutase levels were expressed as mean \pm SD. The levels were compared between the Study and Control groups by student's t-test or Mann 2 Whitney U test was used for comparison of numeric variables between two groups. Comparison between RDS group was determined by one-way analysis of variance (ANOVA) followed by Tukey post hoc test for multiple comparisons. Probability values (P) less than 0.05 were considered to be statistically significant.

\section{Results:-}

\section{Characteristics of the studied groups:}

The study included 40 premature neonates with RDS and 50 healthy premature neonates. $75 \%$ of RDS group were delivered by cesarean and $57.5 \%$ of them were infant of diabetic mothers. $65 \%$ of RDS group and $42 \%$ of control group were male table (1).

Table (1):-Characteristics of the studied neonates and their mothers: data are presented as number(percentage) and mean $\pm \mathrm{SD}$

\begin{tabular}{|l|l|l|}
\hline & RDS group $\mathrm{n}=40$ & Control group $\mathrm{n}=50$ \\
\hline $\begin{array}{l}\text { Maternal history N (\%) } \\
\text { Vaginal }\end{array}$ & $10(25 \%)$ & \\
Cesarean & $30(75 \%)$ & $23(46 \%)$ \\
Maternal history of diabetes & $23(57.5 \%)$ & $27(54 \%)$ \\
Maternal history of hypertension & $5(12.5 \%)$ & $4(8 \%)$ \\
& $26(65 \%)$ & $6(12 \%)$ \\
Sex N (\%) & $14(35 \%)$ & $21(42 \%)$ \\
Male & $29.6 \pm 1.5$ & $29(58 \%)$ \\
Female & $1054 \pm 356$ & $30 \pm 2.6$ \\
mean \pm SD & $6.75 \pm 1.34$ & $1324 \pm 199$ \\
Gestational age (weeks) & $7.94 \pm 1.12$ & 8 \\
Birth weight (g) & & 9 \\
\hline Apgar score & & \\
1 minute & & \\
5 minutes & & \\
\hline
\end{tabular}


Difference in oxidative markers between RDS and control groups:

High significant changes in mean \pm SD of oxidative markers between both groups were observed. Significant increase in oxidant markers (MDA, TBRAS)was detected in RD group when compared with control group and significant decrease in antioxidant markers (GHS, SOD) table (2).

Table (2):-oxidative stress markers of all studied groups

\begin{tabular}{|l|l|l|l|l|}
\hline & $\begin{array}{l}\text { MDA } \\
\text { Nmol/ml }\end{array}$ & $\begin{array}{l}\text { TBRAS } \\
\mu \mathrm{mol} / \mathrm{l}\end{array}$ & $\begin{array}{l}\text { Reduced GSH } \\
\mu \mathrm{mol} / \mathrm{gHb}\end{array}$ & $\begin{array}{l}\text { SOD } \\
\mu / \mathrm{gHb}\end{array}$ \\
\hline RDS group $(\mathrm{n}=40)$ & $4.39 \pm 0.97^{*}$ & $3.49 \pm 2.6^{*}$ & $2.73 \pm 1.63^{*}$ & $348 \pm 45.1^{*}$ \\
\hline $\begin{array}{l}\text { Control group }(\mathrm{n}= \\
50)\end{array}$ & $2.26 \pm 0.26$ & $1.93 \pm 2.5$ & $4.78 \pm 1.6$ & $806 \pm 50.7$ \\
\hline
\end{tabular}

Data are presented as means $\pm S D ; n=$ number of cases in each group. Statistical analysis was done using student's t-test. *, $P<0.05$ versus control

Difference in oxidative stress markers according to severity of RDS:

Mean \pm SD levels of oxidant markers MDA, and TBRAS were significantly increased in moderate and sever cases of RDS when compared with mild cases. Also, the antioxidant markers GSH, and SOD were significantly decreased in sever/moderate cases when compared with mild cases $p<0.05$.

Table (3):-measurement of oxidative markers in mild, moderate and sever cases of RDS.

\begin{tabular}{|l|l|l|l|l|}
\hline & $\begin{array}{l}\text { MDA } \\
\text { Nmol/ml }\end{array}$ & $\begin{array}{l}\text { TBRAS } \\
\mu \mathrm{mol} / 1\end{array}$ & $\begin{array}{l}\text { Reduced GSH } \\
\mu \mathrm{mol} / \mathrm{gHb}\end{array}$ & $\begin{array}{l}\text { SOD } \\
\mu / \mathrm{gHb}\end{array}$ \\
\hline Mild RDS (n=15) & $3.9 \pm 0.89$ & $1.86 \pm 1.9$ & $4.01 \pm 0.2$ & $460.1 \pm 20.5$ \\
\hline $\begin{array}{l}\text { Moderate RDS }(\mathrm{n}= \\
12)\end{array}$ & $4.4 \pm 0.2$ & $4.2 \pm 2.1$ & $3.42 \pm 1.9$ & $390 \pm 29$ \\
\hline Sever RDS (n=13) & $5.21 \pm 0.1$ & $5.1 \pm 1.2$ & $1.9 \pm 1.7$ & $387 \pm 19.8$ \\
\hline P value & $0.00^{*}$ & $0.00^{*}$ & $0.001^{*}$ & $0.00^{*}$ \\
\hline F & 19.136 & 12.559 & 7.968 & 44.945 \\
\hline
\end{tabular}

Data are presented as means $\pm S D ; n=$ number of cases in each group. Statistical analysis was done using one-way ANOVA followed by Tukey post-hoc test for multiple comparisons. *, $P<0.05$

\section{Discussion:-}

The imbalance between reactive oxygen species (ROS) and enzymes needed for removal of free radicals is called oxidative stress. This process involved in the activation of a complexarray of genes involved in inflammation,coagulation, fibrinolysis, cell cycle andsignal transduction resulting in consequence on fetal structure.The rapid transition of the fetus from a relatively hypoxic to a relatively hyperoxic environment at birth gives rise to oxidative stress. However, oxidant defense mechanisms are induced late in gestation.Management of oxidative stress is a greatchallenge for both researchers and clinicians(Frank, 1991; Dizdar et al., 2011).

In the present study, we detected evidence of oxidative stress in cord blood of premature neonates suffering from RDS that was prominent with severe cases. Most of RDS cases in the present work were delivered by Caesarean section and some of them were infants of diabetic mothers. Substantial increased levels of oxidant markers MDA and TBARS in our study were accompanied with significant decreased levels of GHS and SOD.

Many authors have demonstrated that there is the same degree of fetal oxidative stress in vaginal delivery as that resulting from Caesarean section (Fogel et al., 2005; Hracsko et al., 2007). It is unclear whether oxidative stress is related to delivery itself or whether it reflects a pre-existing fetal level of oxidative status. Laurie et al. (2007) demonstrated that distressed fetuses delivered by emergency Caesarean section exhibited increased MDA concentrations, an indicator of lipid oxidative damage, and enhanced glutathione peroxidase (GPX), an antioxidant enzyme, in amniotic fluid and umbilical cord blood compared with non-distressed fetuses delivered by vaginal delivery. These findings are suggestive of elevated fetal oxidative stress (Georgeson et al., 2002; Laurie et al., 2007).

Orhan et al. (2003) implies that TBARS is one of thepromising clinical markers of oxidative stress. They detected increased TBARS and decreased GHS levels in infant of diabetic mother and concluded the concept of oxidative 
stress in diabetic pregnancies. These conclusions were in line with our results where most of RDS group were infant of diabetic motherbut it is in disagreement with Kinalski et al. (2001) whofound significantly higher levels of GSH in umbilicalcord blood of infants of mothers suffering from diabetes mellitus.

Respiratory distress syndrome is accompanied by inflammatory processes with free radical generation and oxidative stress (Nemeth, 1994, Krediet, 2006). The imbalance between the oxidative forces and the antioxidant defense systems was suggested to predispose the lungs to the development of RDS (Lang et al., 2002). Many studies have shown increased oxidant stress markers and/or reduced antioxidant defense in preterm infants with RDS (Ogihara et al., 1996, Miller et al., 1993).

Malondialdehyde (MDA) is one of the final products of polyunsaturated fatty acids peroxidation. The present study showed increased concentration of MDA in neonates with respiratory disorders than that of control in consonance with the reported study(Negi et al., 2015 ).In addition, preterm infants appear to have deficient quantities of enzymes responsible for scavenging ROS, including superoxide dismutase. Frank, (1987).

ROS potentiate tissue damage by lipid peroxidation (Saugstad, 2005). A common site of damage is the basement membrane and other elements of the lung matrix. One consequence of this damage is increased microvascular permeability and vascular leakage, resulting in oedema formation containing protein rich fluid(Groneck et al., 1994). This protein rich fluid is consideredas an ideal target for oxygen reactive species. In order to initiate the oxidative attack, ROScauses an imbalance in the lung protease-antiprotease system through inactivation of alpha-1 protease [Saugstad, 2000; Winterbourn, 2001].ROS also interact with pulmonary surfactant as well as with other protein and lipid structures, thus delaying the normal functioning of the lung. Therefore, surfactant administration before the initiation of mechanical ventilation diminishes the severity of lung lesions by providing consistent ventilation [Carty et al., 2000]. This oxidation process has been proven to contribute to pathogenesis in newborns with RDS [Buonocore et al., 2000].

The present study observed reduction in total antioxidant status in newborns with RDS compared to healthy newborns. One study also reported decreased level of total antioxidant activity in newborn with RDS (Dizdar et al., 2011). Oxidant-antioxidant balance shifts in favor of the oxidative damage in premature newborns with RDS due to diminished antioxidant activity. Antioxidant defenses of the immature lung will be prepared neither for the hyperoxic environment nor the inflammation found in association with respiratory distress(Davis and Auten, 2010). The lung depends on a delicate balance between oxidant and antioxidant systems to maintain normal cellular function. The lungs of prematurely born infants suffering from respiratory distress syndrome may be ill-adapted for protection against ROS. Antioxidants clearly have an important role in the defense against free radical induced lung injury in newborns with RDS(Negi eta ., 2015).

The present study showed that the elevated level ofMDA and TBRAS might be risk factor; reduced level of total antioxidant status (reduced GHS and SOD) might lead to the RDS in newborn and control its severity. Total antioxidant status might serve as prognostic marker in newborns with RDS and might help distinguish high risk infants.

\section{Conclusion:-}

The result of this study indicates that newborns with RDS were manifested by oxidative stress accompanied by reduced antioxidant defenses which could play a role in the pathogenesis of RDS and affect its degree of severity.

\section{References:-}

1. Beutler E, Duran O, Kelly BM: Improved method for the determination of blood glutathione. J Lab Clin Med. 1963; 51: 882-888.

2. Boda D., Nemeth I., Pinter S. Surface tension, glutathione content and redox ratio of the tracheal aspirate fluid of premature infants with IRDS. Biol. Neonate. 1998;74:281-288.

3. Buonocore G., Perrone S., Longini M. Total hydroperoxide and advanced oxidation protein products in preterm hypoxic babies. Pediatr. Res. 2000;47:1-4.

4. Carty J.L., Bevan R., Waller H. The effects of vitamin C supplementation on protein in healthy volunteers. Biochem. Res. Com. 2000;273:729-735. 
5. Davis JM, Auten RL. Maturation of the antioxidant system and the effects on preterm birth. Semin Fetal Neonatal Med 2010;15:191 -5.

6. Dizdar E.A., Uras N., Oguz S., Erdeve O., Sari F.N., Aydemir C., Dilmen U. Total antioxidant capacity and total oxidant status after surfactant treatment in preterm infants with respiratory distress syndrome. Ann. Clin. Biochem. 2011;48:462-467.

7. Esteban J., Morcillo J.E., Cortjo J. Oxidative stress and pulmonary inflammation: pharmacological intervention with antioxidants. Pharmacol. Res. 1999;40:393-404.

8. Fogel I, Pinchuk I, Kupferminc MJ, et al. Oxidative stress in the fetal circulation does not depend on mode of delivery. Am J ObstetGynecol 2005;193:241-246.

9. Frank L, Sosenko IR. Development of lung antioxidant enzyme system in late gestation: possible implications for the prematurely born infant. J Pediatr 1987;110:9-14.

10. Frank L. Developmental aspects of experimental pulmonary oxygen toxicity. Free RadicBiol Med 1991;11:463 $-94$

11. Georgeson GD, Szony BJ, Streitman K, et al. Antioxidant enzyme activities are decreased in preterm infants and in neonates born via caesarean section. Eur J ObstetGynecolReprodBiol 2002;103:136 - 9

12. Gitto E., R. J. Reiter, S. P. Cordaro et al., "Oxidative and inflammatory parameters in respiratory distress syndrome of preterm newborns: beneficial effects of melatonin," American Journal of Perinatology, vol. 21, no. 4, pp. 209-216, 2004.

13. Gleason C. A. and S. U. Devaskar, Avery's Diseases of the Newborn, Elsevier Health Sciences, New York, NY, USA, 9th edition, 2012.

14. Groneck P, Gotze-Speer B, Oppermann M, et al. Association of pulmonary inflammation and increased microvascular permeability during the development of bronchopulmonary dysplasia: a sequential analysis of inflammatory mediators in respiratory fluids of high-risk preterm neonates. Pediatrics 1994;93:712-18.

15. Hracsko Z, Safar Z, Orvos H, et al. Evaluation of oxidative stress markers after vaginal delivery or caesarean section. In Vivo 2007;21:703-706.

16. Huertas J.R., Palomino N., Ochoa J.J. Lipid peroxidation and antioxidant erythrocyte membranes of full-term and preterm newborns. Biofactors. 1998;8:133-137.

17. Ikegami M., Kallapur S., Michna J., Jobe A.H. Lung injury and surfactant metabolism after hyperventilation of premature lambs. Pediatr. Res. 2000;47:398-404.

18. Kinalski M, Sledziewski A, Telejko B, Kowalska I, Kretowski A, Zarzycki W, KinalskaI I: Lipid peroxidation, antioxidant defence and acid-base status in cord blood at birth: the influence of diabetes. HormMetab Res 33: 227-231, 2001.

19. Krediet T.G., Cirkel G.A., Vreman H.J., Wong R.J., Stevenson D.K., Groenendaal F., Egberts J., Van Bel F. End-tidal carbon monoxide measurements in infant respiratory distress syndrome. ActaPaediatr. 2006;95:10751082.

20. Lang J.D., McArdle P.J., O'Reilly P.J., Matalon S. Oxidant-antioxidant balance in acute lung injury. Chest. 2002;122:314S-320S.

21. Laurie S, Mataz Z, Boaz M, et al. Different degrees of fetal oxidative stress in elective and emergent caesarean section. Neonatology 2007;92:111-115.

22. Marklund S, Marklund G: Involvement of superoxide anion radical in the auto-oxidation of pyrogallol and a convenient assay of superoxide dismutase. Eur J Biochem. 1974, 47: 469-474.

23. Marseglia L., G. D'Angelo, S. Manti et al., "Oxidative stress-mediated aging during the fetal and perinatal periods," Oxidative Medicine and Cellular Longevity, vol. 2014,

24. Miller N.J., Rice Evans C., Davies M.J., Gopinathan V., Milner A. A novel method for measuring antioxidant capacity and its application to monitoring the antioxidant status in premature neonates. Clin. Sci. 1993;84:407412.

25. Mutinati M., M. Pantaleo, M. Roncetti, M. Piccinno, A. Rizzo, and R. L. Sciorsci, "Oxidative stress in neonatology: a review," Reproduction in Domestic Animals, vol. 49, no. 1, pp. 7-16, 2014.

26. Nandi A, Chatterjee IB: Assay of superoxide dismutase activity in animal tissue. J Biosci. 1988, 13: 305-315.

27. Negi R, Pande D, Karki K, Kumar A, Khanna RS, Khanna HD A novel approach to study oxidative stress in neonatal respiratory distress syndrome. BBA Clin. 2015 Jun; 3: 65-69.

28. Nemeth I., Boda D. Blood glutathione redox ratio as a parameter of oxidative stress in premature infants with IRDS. Free. Radic. Biol. Med. 1994;16:347-353.

29. Ogihara T., Okamoto R., Kim H.S. New evidence for the involvement of oxygen radicals in triggering neonatal chronic lung disease. Pediatr. Res. 1996;39:117-119. 
30. Orhan H, Öndreroglu L, Yucel A, Sahin G: Circulating biomarkers of oxidative stress in complicated pregnancies. Arch GynecolObstet 267: 189-195, 2003.

31. Rahal A., A. Kumar, V. Singh et al., "Oxidative stress, prooxidants, and antioxidants: the interplay," BioMed Research International, vol. 2014, Article ID 761264, 19 pages, 2014.

32. Rodriguez R.J., R.J. Martin, A.A. Fanaroff, Respiratory distress syndrome and its management, in: Fanaroff, Martin (Eds.), Neonatal-Perinatal Medicine: Diseases of the Fetus and Infant, Mosby, St. Louis, 2002, pp. 1001-1011.

33. Satoh K: Serum lipid peroxide in cerebrospinal disorder determined by a new colorimetric method. ClinChimActa. 1978, 40: 37-43.

34. Saugstad O.D. Update on oxygen radical disease in neonatology. Curr. Opin. Obstet. Gynecol. 2001;13:147153.

35. Saugstad OD. Bronchopulmonary dysplasia - oxidative stress and antioxidants. SeminNeonatol 2003;8:39-49.

36. Saugstad OD. Oxidative stress in the newborn. A 30-year perspective. Biol Neonate 2005;88:228-236

37. Saugstad OD. Oxidative stress in the newborn: a 30-year perspective. Biol Neonate 2005;88:228-36.

38. Winterbourn C.C., Chan T., Buss I.H., Inder T.E., Mogridge N., Darlow B.A. Protein carbonyls and lipid peroxidation products as oxidation markers in preterm infant plasma: association with chronic lung disease and retinopathy and effects of selenium supplementation. Pediatr. Res. 2000;48:84-90. 